\title{
A diagnostic marker set for invasion, proliferation, and aggressiveness of prolactin pituitary tumors
}

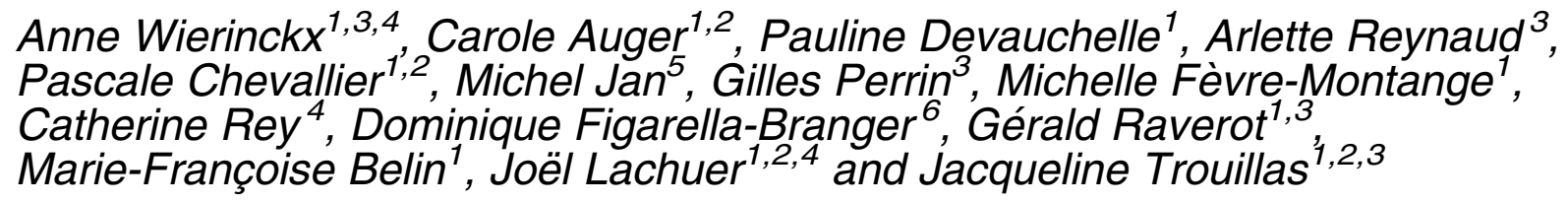

${ }^{1}$ INSERM, U842, Lyon F-69372 France

${ }^{2}$ Faculté de Médecine Laennec, Université de Lyon, Lyon1, Lyon F-69372, France

${ }^{3}$ Hospices Civils de Lyon, Lyon F-69003, France

${ }^{4}$ ProfileXpert, Neurobiotec Service, Bron F-69500, France

${ }^{5}$ Département de Neurochirurgie, Faculté de Médecine, Université de Tours, Tours F-37000, France

${ }^{6}$ Faculté de Médecine, Hôpital la Timone Adultes, Université de la Méditerranée, Marseille F-13385, France

(Correspondence should be addressed to J Trouillas, U842 Faculté de Médecine Laennec rue G Paradin 69372 Lyon France; Email: jacqueline.trouillas@ recherche.univ-lyon1.fr)

C Auger, P Devauchelle, J Lachuer and J Trouillas contributed equally to this work

\begin{abstract}
Although most pituitary tumors are benign, some are invasive or aggressive. In the absence of specific markers of malignancy, only tumors with metastases are considered malignant. To identify markers of invasion and aggressiveness, we focused on prolactin (PRL) tumors in the human and rat. Using radiology and histological methods, we classified 25 human PRL tumors into three groups (non-invasive, invasive, and aggressive-invasive) and compared them with a model of transplantable rat PRL tumors with benign and malignant lineages. Combining histological (mitoses and labeling for Ki-67, P53, pituitary transforming tumor gene (PTTG), and polysialic acid neural cell adhesion molecule) and transcriptomic (microarrays and q-RTPCR) methods with clinical data (post-surgical outcome with case-control statistical analysis), we found nine genes implicated in invasion (ADAMTS6, CRMP1, and DCAMKL3) proliferation (PTTG, ASK, CCNB1, AURKB, and CENPE), or pituitary differentiation (PITX1) showing differential expression in the three groups of tumors $(P=0.015$ to 0.0001$)$. A case-control analysis, comparing patients in remission (9 controls) and patients with persistent or recurrent tumors (14 cases) revealed that eight out of the nine genes were differentially up- or downregulated ( $P=0.05$ to 0.002$)$, with only PTTG showing no correlation with clinical course $(P=0.258)$. These combined histological and transcriptomic analyses improve the pathological diagnosis of PRL tumors, indicating a reliable procedure for predicting tumor aggressiveness and recurrence potential. The similar gene profiles found between non-invasive human and benign rat tumors, as well as between aggressive-invasive human and malignant rat tumors provide new insights into malignancy in human pituitary tumors.
\end{abstract}

Endocrine-Related Cancer (2007) 14 887-900

\section{Introduction}

Tumors occur frequently in the pituitary, but are generally considered benign. However, many (45-55\%) invade the sphenoid, cavernous sinus, or dura mater (Meij et al. 2002), and some are described as aggressive with a high proliferation rate and short postoperative time to recurrence. Only $0.2 \%$ of all pituitary tumors with subarachnoid, brain, or systemic metastasis are considered malignant (Kaltsas et al. 2005). The prediction of pituitary tumor behavior remains a challenge (Figarella-Branger \& Trouillas 2006, Grossman 2006, Gurlek et al. 2007), and factors known to be involved in pituitary tumorigenesis are not predictive of invasiveness or aggressiveness (Al-Shraim \& Asa 2006). These factors include classical proliferative markers (Ki-67, proliferation 
cell nuclear antigen, and P53; Knosp et al. 1989, Hsu et al. 1993, Levy et al. 1994, Jaffrain-Rea et al. 2002), putative oncogenes (pituitary transforming tumor gene (PTTG) and Ras; Pei et al. 1994, Pei \& Melmed 1997), growth factors (fibroblast growth factor (FGF) and vascular endothelial growth factor; Lloyd et al. 1999, Ezzat et al. 2002), and one marker of invasion (polysialic acid neural cell adhesion molecule (PSANCAM); Trouillas et al. 2003). The limited usefulness of these markers is probably due to their multiple functions in normal pituitary plasticity and misunderstanding of the switch from their physiological function to their role in tumor behavior. Other limitations in determining the criteria of invasiveness and aggressiveness include the anatomic location of the pituitary, the existence of several tumoral cell phenotypes, extrinsic or intrinsic factors involved in pituitary tumors, and the paucity of in vitro or in vivo tumor models.

To identify markers of invasion or aggressiveness and find prognostic markers of pituitary tumors, we focused on prolactin (PRL) tumors and used a combination of histological and transcriptomic approaches in human tumors and a tumor rat model as previously described (Trouillas et al. 1990, 1999). We used 25 human PRL tumors carefully classified into three groups (non-invasive, invasive, and aggressive-invasive) by radiology using magnetic resonance imaging (MRI) and histology (including Ki-67, mitosis, PTTG, P53, and PSA-NCAM) alongside the post-surgical outcome available for 23 out of the 25 patients. In contrast to other models of pituitary tumors, the spontaneous mammotropic transplantable tumors in Wistar/Furth rats (SMtTW) are derived from spontaneous rat pituitary tumors and are similar to human PRL tumors (Trouillas et al. 1990, Daniel et al. 2000). The primary tumor and the tumors transplanted under the kidney capsule form a lineage. In this study, two lineages were used: one remaining benign (non-invasive) and the other becoming malignant (invasive and metastatic) after several passages.

A supervised microarray transcriptomic study was performed on the human and rat PRL tumors to identify genes differentially expressed in human noninvasive, invasive, and aggressive-invasive tumors and in rat benign or malignant tumors. These combined histological and transcriptomic approaches made it possible to establish a set of markers that discriminated between the three groups of human PRL tumors also differing in post-surgical outcome. The existence of similar markers in human aggressive-invasive tumors and rat malignant tumors provides new insights into malignancy in human PRL tumors.

\section{Materials and methods}

\section{Human pituitary tumors}

Fragments of each pituitary tumor in our collection were embedded in paraffin for pathological diagnosis and many were frozen (Neurobiotec Bank, Lyon, France). Of the frozen tumors, we selected 25 PRLproducing tumors, with plasma PRL levels $>200 \mu \mathrm{g} / \mathrm{l}$ and only PRL immunostaining (plurihormonal PRL tumors being excluded) removed by the transsphenoidal approach between 1994 and 2004. Dopamine response was tested in 16 out of the 25 patients. The resistance was defined as previously published (Delgrange et al. 1997, 2005). The medical therapy was interrupted at least 2 months before surgery.

From MRI data, the tumoral volume was calculated according to the formula: height $\times$ length $\times$ width $/ 2$. The invasion of the cavernous or sphenoid sinus was identified in 14 tumors.

The post-surgical outcome was available for 23 out of the 25 patients. Postoperative follow-up time ranged from 27 to 152 months (mean: 93 months). Patients showing no clinical or hormonal (PRL $<30 \mathrm{ng} / \mathrm{ml}$ ) symptoms and no radiological remnant were considered in remission. The persistence of increased plasma levels with or without radiological mass defined the status of persistence. Tumoral recurrence was defined as the radiological evidence of regrowth of a tumor remnant.

For gene expression analysis, to avoid contamination, the surrounding normal pituitary of each non-invasive microadenoma was macroscopically discarded by manual dissection. Because normal pituitary is difficult to distinguish from tumor, its absence was checked on frozen sections: the cordonal arrangement of the normal pituitary contrasting from the usual diffuse organization of the tumor.

These 25 tumors and normal pituitary were also controlled by q-RTPCR for five genes encoding: 1) PRL and growth hormone $(\mathrm{GH})$ to eliminate $\mathrm{GH}$ and PRL co-secretion; 2) proopiomelanocortin and luteinizing hormone $\beta$ to ensure no contamination with normal pituitary; and 3) a housekeeping gene (RPLA) stably expressed in the different human samples and used as an internal control for all subsequent q-RTPCR analyses. All the tumor samples showed high $P R L$ gene expression and no signal for the other hormone-encoding genes.

\section{SMtTW tumor model}

Female Wistar/Furth WF/Ico inbred rats were used (Charles River laboratories, L'Arbresle, France). SMtTW lineages were generated from spontaneous PRL tumors, which were grafted under the kidney 
capsule in female consanguineous rats. The main characteristics of the strain and the grafting procedure have previously been described in detail (Trouillas et al. 1990). Each lineage was maintained by serial tumor grafts; passages are defined as the number of subsequent transplantations under the kidney capsule. In this study, we used two different SMtTW tumor lineages, $\mathrm{SMtTW}_{2}$ and $\mathrm{SMtTW}_{3}$.

The $\mathrm{SMtTW}_{2}$ tumor lineage was benign, exhibiting no signs of malignancy up to at least 26 passages. The tumors remained circumscribed, with no invasion of the kidney or surrounding tissues. Their growth rate was low with high secretion levels of PRL $(8.1 \mu \mathrm{g} / \mathrm{ml})$.

The $\mathrm{SMtTW}_{3}$ lineage had a PRL phenotype with high plasma PRL levels $(9.3-161 \mu \mathrm{g} / \mathrm{ml})$ and a low secretion of $\mathrm{GH}(0.07 \mu \mathrm{g} / \mathrm{ml})$. The $\mathrm{SMtTW}_{3}$ tumors changed during passaging; during passages $3-11$, they seemed benign, but grew more rapidly than the $\mathrm{SMtTW}_{2}$ tumors, and nodules were sometimes seen around the grafted kidney. After the 34 th passage, $\mathrm{SMtTW}_{3}$ tumors grew very rapidly, invading the surrounding tissues, and were frequently necrotic and metastatic.

For gene expression analysis, tumor fragments were taken from the most cellular areas of the tumor with no necrosis or fibrosis, and stored frozen at $-80{ }^{\circ} \mathrm{C}$ until later use. Eighteen tumors were analyzed from the $\mathrm{SMtTW}_{2}$ lineage (seven tumors taken at random) and the $\mathrm{SMtTW}_{3}$ lineage (seven tumors with premalignant behavior $\left(\mathrm{SMtTW}_{3 \mathrm{pm}}\right)$ and four with malignant behavior $\left(\mathrm{SMtTW}_{3 \mathrm{~m}}\right)$ ).

\section{Immunohistochemistry}

PRL and proliferation marker detection was performed on paraffin sections of tissue fixed in Bouin Holland using the indirect immunoperoxidase method with a Vectastain ABC Kit (Vector, Burlingame, CA, USA). The following antibodies were tested: human anti-PRL (1/400; Immunotech, Marseille, France), rat anti-PRL from Dr Parlow (1/8000; NIDDK, Bethesda, MD, USA), Ki-67 (Mib1 (1/50; Dako, Glostrup, Denmark) for human tumors, MM1 1/200 (Novocastra Laboratories, Newcastle Upon Tyne, UK) for SMtTW tumors, anti-p53 (1/200, Novocastra), anti-PTTG (1/200, Zymed Laboratories Inc., San Francisco, CA, USA), and anti-galectin-3 (1/200; Novocastra). For the last four antibodies, the sections were heated 3 times for $5 \mathrm{~min}$ in $10 \mathrm{mM}$ citric acid $(\mathrm{pH} \mathrm{6})$ at $750 \mathrm{~W}$ in a microwave oven. To determine both the Ki-67 labeling and mitotic indexes, cells were counted at $400 \times$ magnification in ten representative fields per tumor, with an average count of 5000 nuclei.
For PSA-NCAM detection, cryostat sections were incubated with an anti-PSA-NCAM (1/1000; AbCys SA, Paris, France) as previously described (Daniel et al. 2000). Immunoperoxidase staining was performed using the Vectastain ABC Kit (mouse IgM, Vector) and 3-amino-9-ethylcarbazole chromogen (Dako).

Detection of PRL, proliferative markers, and PSANCAM was performed on all human tumors and at least ten rat tumors of each lineage taken at different passages, except for galectin-3, PTTG, and p53, for which no antibody against the rat protein was available.

\section{RNA extraction}

Total RNA was extracted from human or rat pituitary tumors using Trizol, according to the manufacturer's protocol (Invitrogen). For q-RTPCR, total RNA was subjected to DNase treatment using an RNeasy minikit (Qiagen) according to the manufacturer's protocol. Total RNA yield was measured by $\mathrm{OD}_{260}$, the purity was checked by an A260/A280 ratio of 1.9-2.1, and the quality was evaluated on nanochips with the Agilent 2100 Bioanalyzer (Agilent Technologies, Palo Alto, CA, USA) according to the manufacturer's protocol.

\section{RNA amplification}

Total RNA ( $2 \mu \mathrm{g})$ was amplified and biotin labeled by a round of in vitro transcription (dIVT) with a Message Amp aRNA kit (Ambion, Austin, TX, USA) following the manufacturer's protocol. Before amplification, spikes of synthetic mRNA at different concentrations were added to all samples; these positive controls were used to ascertain the quality of the process. aRNA yield was measured with a u.v. spectrophotometer and the quality on nanochips with the Agilent 2100 Bioanalyzer (Agilent).

\section{Array hybridization and processing}

Ten micrograms of biotin-labeled aRNA were fragmented using $5 \mu \mathrm{l}$ fragmentation buffer in a final volume of $20 \mu \mathrm{l}$, then mixed with $240 \mu \mathrm{l}$ Amersham hybridization solution (GE Healthcare Europe GmbH, Freiburg, Germany) and injected onto CodeLink Uniset Human Whole Genome bioarrays containing 55000 human oligonucleotide gene probes or CodeLink Uniset Rat Whole Genome bioarrays containing 36000 rat oligonucleotide gene probes (both from GE Healthcare Europe GmbH, Munich, Germany). Arrays were hybridized overnight at $37^{\circ} \mathrm{C}$ at $15 \mathrm{~g}$ in an incubator. The slides were washed in stringent TNT buffer at $46{ }^{\circ} \mathrm{C}$ for $1 \mathrm{~h}$ before performing a streptavidin-cy5 (GE Healthcare) detection step. Each slide was incubated for $30 \mathrm{~min}$ in $3.4 \mathrm{ml}$ streptavidin-cy5 
solution as previously described (Fevre-Montange et al. 2006), washed four times in $240 \mathrm{ml}$ TNT buffer, rinsed twice in $240 \mathrm{ml}$ water containing $0.2 \%$ Triton $\mathrm{X}-100$, and then dried by centrifugation at $650 \mathrm{~g}$.

The slides were scanned using a Genepix 4000B scanner (Axon, Union City, CA, USA) and Genepix software, with the laser set at $635 \mathrm{~mm}$, the laser power at $100 \%$, and the photomultiplier tube voltage at $60 \%$. The scanned image files were analyzed using CodeLink expression software, version 4.0 (GE Healthcare), which produces both a raw and a normalized hybridization signal for each spot on the array.

\section{Microarray data analysis}

The relative intensity of the raw hybridization signal on arrays varies in different experiments. CodeLink software was therefore used to normalize the raw hybridization signal on each array to the median of the array (median intensity is 1 after normalization) for better cross-array comparison. The threshold of detection was calculated using the normalized signal intensity of the 100 negative control samples in the array; spots with signal intensities below this threshold were referred to as 'absent'.

The quality of processing was evaluated by generating scatter plots of positive signal distribution. Signal intensities were then converted to $\log$ base 2 values. Statistical comparison and filtering were performed using Genespring software 7.0 (Agilent Technology, Santa Clara, CA, USA). The expression of the genes in the normal pituitary was used as the standard and set to 1 .

\section{Reverse transcription}

Total RNA $(0.5 \mu \mathrm{g})$ was reverse transcribed using MMLV reverse transcriptase (Invitrogen). The absence of contaminating genomic DNA in the RT reactions was checked by q-RTPCR directly on total RNA.

\section{Q-RTPCR}

The cDNA synthesized was measured using q-RTPCR (SYBR Green PCR, LightCycler, Roche Diagnostics Indianapolis) following the manufacturer's recommendations. The LightCycler experimental run protocol consisted of an initial Taq activation at $95^{\circ} \mathrm{C}$ for $10 \mathrm{~min}$ and 45 cycles of the amplification and quantification program $\left(95{ }^{\circ} \mathrm{C}\right.$ for $15 \mathrm{~s}, 60^{\circ} \mathrm{C}$ for $5 \mathrm{~s}$, and $72{ }^{\circ} \mathrm{C}$ for $10 \mathrm{~s}$, with a single fluorescence measurement). The specificity of PCR amplification was always analyzed with a melting curve program $\left(69-95^{\circ} \mathrm{C}\right)$ with a heating rate of $0.1^{\circ} \mathrm{C}$ per second and continuous fluorescence measurement. Primers were designed with Primer3 software
(Whitehead Institute/MIT, USA) and purchased from Eurogentec (Seraing, Belgium). All primers had Tms between 59 and $61{ }^{\circ} \mathrm{C}$ and all the products were 100 $150 \mathrm{bp}$.

\section{Analysis of the Q-RTPCR}

The internal standards used to control amplification variations due to differences in the starting mRNA concentration were ribosomal protein L4 (RPL4) mRNA for the human samples and glyceraldehyde-3phosphate dehydrogenase (GAPD) and YWHAE mRNAs for rat samples. The relative mRNA levels for each tissue were computed from the $C_{\mathrm{t}}$ values obtained for the gene of interest, the efficiency of the primer set, and RPL4 mRNA levels in human samples and the average of the GAPD and YWHAE mRNA levels in rat samples using RealQuant software (Roche).

\section{Statistical analysis}

For pathological data, the Kruskal-Wallis test and the Tukey test were used for comparison of means (Ki-67 indexes and percentage of mitoses). The mean percentages of nuclear labeling with PTTG and P53 were compared by Fisher's exact test.

For microarray data, statistical comparison and filtering were performed using Genespring software 7.0 (Agilent). Pairwise comparisons were performed between non-invasive and invasive tumors, noninvasive and aggressive-invasive tumors, and invasive and aggressive-invasive tumors. Each sample from one group was compared with each sample from the other group, and only genes showing a variation of average fold change $\geq 2$ were retained. A given mRNA transcript was considered as differentially expressed in the comparison of any two samples if the difference gave a $P$ value of $\leq 0.05$ in the Welch ANOVA parametric test, using a multiple test correction (Benjamini and Hochberg False Discovery Rate). Thus, a gene was considered as differentially expressed between tumor groups only if it met the above criteria in all pairwise comparisons and if the detected signal was above the background for at least one of the compared tumor groups, thereby carrying a statistically significant absolute call 'present' or 'marginal' in all samples.

To evaluate the diagnostic and prognostic values of the nine selected genes, the comparison of the mean values obtained by q-RTPCR of each gene between the three groups of tumors were performed using the KruskalWallis test. In a case-control study (control, patient in remission; case, patient with persistent or recurrent tumors), the comparison of the mean values obtained by 
q-RTPCR of each gene between control and case were performed using the non-parametric Mann-Whitney test.

For all statistical tests, a difference with a $P$ value of $\leq 0.05$ was considered significant.

\section{Results}

\section{Classification of human PRL tumors}

The 25 human PRL tumors were classified by radiology and histology (Table 1; Fig. 1).

By radiology, these 25 PRL tumors consisted of 11 non-invasive adenomas (including three macroadenomas: nos 4, 7, and 10) and 14 invasive macroadenomas (volume $>0.5 \mathrm{~cm}^{3}$ ) with histological proof of invasion in six of them.

By histology, the detection of four markers of proliferation (mitosis, Ki-67, PTTG, and P53) and a marker of invasion (PSA-NCAM) confirmed that no marker per se could distinguish between invasive and non-invasive tumors. However, mitoses and Ki-67 labeling were significantly different in five invasive tumors (no. 20-25) $(P=0.01$ and 0.001 respectively). P53 and PTTG nuclear labeling was also statistically different $(P<0.0001)$. We classified these five invasive tumors with high indexes of Ki-67, nuclear labeling of PTTG, and P53 as aggressive-invasive tumors. They correspond to the 'atypical adenoma' briefly mentioned in the World Health Organization (WHO) classification (Lloyd et al. 2004).

The results of these pathological studies combined with the radiological analysis are consistent with the existence of three groups of PRL tumors: non-invasive, invasive, and aggressive-invasive tumors.

\section{Pathological classification of SMtTW rat tumors}

The main characteristics of the two SMtTW lineages are shown in Table 2 and Fig. 2.

Table 1 Main characteristics and classification of the human prolactin (PRL) tumors

\begin{tabular}{|c|c|c|c|c|c|c|c|c|c|c|}
\hline Case & Sex & $\begin{array}{c}\text { Tumor } \\
\text { size }\left(\mathrm{cm}^{3}\right)\end{array}$ & Inv & $\begin{array}{c}\text { Mitosis } \\
(\% \circ)\end{array}$ & $\begin{array}{c}\mathbf{K i}-67 \\
(\%)\end{array}$ & $\begin{array}{l}\text { PTTG1 } \\
\text { C/N (\%) }\end{array}$ & $\begin{array}{l}\text { P53 } \\
(\%)\end{array}$ & $\begin{array}{l}\text { PSA- } \\
\text { NCAM }\end{array}$ & $\begin{array}{l}\text { DA agonist } \\
\text { sensitivity }\end{array}$ & $\begin{array}{l}\text { Post-surgical } \\
\text { outcome }\end{array}$ \\
\hline \multicolumn{11}{|c|}{ Non-invasive } \\
\hline 1 & $\mathrm{~F}$ & 0.28 & No & 0.8 & $1.5[0-2.8]$ & $\mathrm{C}$ & 0 & nd & $\mathrm{s}$ & Remission \\
\hline 2 & $\mathrm{~F}$ & 0.03 & No & 0 & 0 & $\mathrm{C}$ & 0 & - & nd & Remission \\
\hline 3 & $F$ & 0.06 & No & 0 & 0 & $\mathrm{C}$ & 0 & - & nd & Remission \\
\hline 4 & $M$ & 8 & No & 0 & 0 & $\mathrm{C}$ & 0 & + & $\mathrm{s}$ & Persistence \\
\hline 5 & $\mathrm{~F}$ & 0.03 & No & 0 & 0 & $\mathrm{C}$ & 0 & - & nd & Remission \\
\hline 6 & $\mathrm{~F}$ & 0.03 & No & 0 & 0 & $\mathrm{C}$ & 0 & - & nd & Remission \\
\hline $7^{a}$ & M & 1 & No & 0 & $0.7[0-1.3]$ & C & 0 & + & $\mathbf{s}$ & Remission \\
\hline $8^{a}$ & $\mathbf{F}$ & 0.6 & No & 0.2 & $\mathbf{0}$ & C & 0 & - & $\mathbf{r}$ & Unknown \\
\hline $9^{a}$ & $\mathbf{F}$ & 0.6 & No & 0 & 0 & C & 0 & - & nd & Remission \\
\hline 10 & $\mathrm{~F}$ & 1.6 & No & 0 & 0 & $\mathrm{C}$ & 0 & - & nd & Remission \\
\hline 11 & $\mathrm{~F}$ & 0.26 & No & 0.3 & 0 & $\mathrm{C}$ & 0 & - & nd & Remission \\
\hline \multicolumn{11}{|c|}{ Invasive } \\
\hline 12 & $M$ & 14 & Yes* & 0 & 0.8 & $\mathrm{C}$ & 0 & + & s & Recurrence $102 \mathrm{mo}$ \\
\hline 13 & $\mathrm{~F}$ & $>0.5$ & Yes & 0 & 0 & $\mathrm{C}$ & 0 & - & $r$ & Recurrence $120 \mathrm{mo}$ \\
\hline 14 & M & 8.7 & Yes & 0 & 0 & $\mathrm{C}$ & 0 & - & s & Persistence \\
\hline 15 & $M$ & 4 & Yes* & 0 & 0 & $\mathrm{C}$ & 0 & nd & $r$ & Persistence \\
\hline 16 & $\mathrm{~F}$ & $>0.5$ & Yes & 0.4 & 0 & $\mathrm{C}$ & 0 & nd & nd & Unknown \\
\hline $17^{\mathrm{a}}$ & M & 10 & Yes $^{*}$ & 0 & 0 & C & 0 & + & $\mathbf{s}$ & Persistence \\
\hline $18^{a}$ & M & 24 & Yes* & 0.7 & $0.6[0-1.4]$ & C & 0 & + & $\mathbf{s}$ & Persistence \\
\hline $19^{a}$ & M & 4 & Yes* & 0.8 & $1.8[0-3.3]$ & C & 0 & - & $\mathbf{s}$ & Persistence \\
\hline $20^{\mathrm{a}}$ & M & 11.8 & Yes & 0.3 & $1.8[0-3]$ & C & 0 & + & $\mathbf{s}$ & Persistence \\
\hline \multicolumn{11}{|c|}{ Aggressive-invasive } \\
\hline 21 & $\mathrm{~F}$ & 10 & Yes & 1.8 & $1.5[0-1.7]$ & $N(0.3)$ & 1 & - & nd & Recurrence $5 \mathrm{mo}$ \\
\hline 22 & $\mathrm{~F}$ & 4 & Yes & 0.6 & $2.8[2.3-3.8]$ & $\mathrm{N}(0.1)$ & 1.3 & - & $s$ & Recurrence $53 \mathrm{mo}$ \\
\hline $23^{a}$ & $\mathbf{F}$ & 4.6 & Yes & 0.2 & $1.8[0-2.7]$ & $N(0.5)$ & 0 & + & $\mathbf{r}$ & Recurrence $21 \mathrm{mo}$ \\
\hline $24^{a}$ & M & 3 & Yes* & 5 & $8.7[0-10]$ & $N(2.6)$ & 2.3 & - & $\mathbf{r}$ & Recurrence $18 \mathrm{mo}$ \\
\hline $25^{a}$ & M & 4.6 & Yes & 2.8 & $5[0-8]$ & $N(1.8)$ & 2.9 & + & $r$ & Recurrence 12 mo \\
\hline
\end{tabular}

Inv, invasion; *, invasion with histological proof; F, female; M, male; DA, dopamine; s, sensitive; r, resistant; nd, not determined; +, positive labeling; -, no labeling; $\mathrm{C}$, cytoplasmic labeling; $\mathrm{N}$, nuclear labeling. The values are the mean with the range in brackets. Delay of recurrence is expressed in month (mo).

${ }^{\text {a }}$ Tumors used for microarray analysis. 


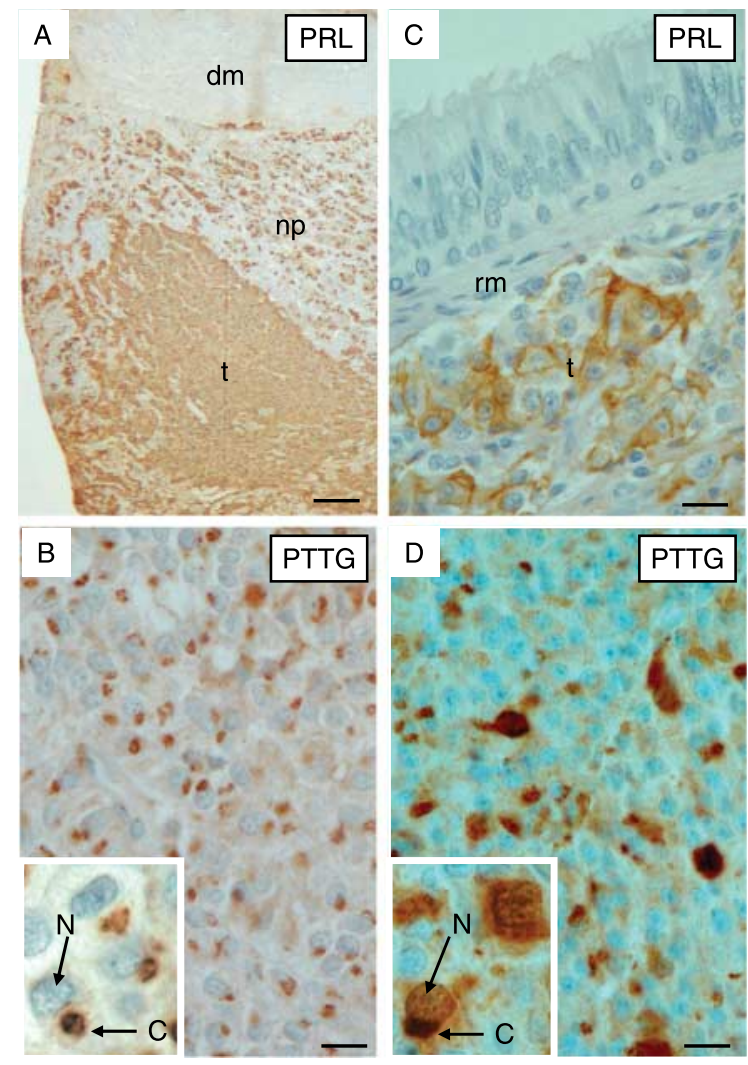

Figure 1 Histological data of human PRL tumors. All the tumoral cells were labeled with anti-PRL $A b(A$ and $C)$. In noninvasive tumor ( $A$ and $B$ ), tumoral cells do not invade the normal pituitary (np) nor the dura mater (dm), but exhibit a cytoplasmic (C) labeling with anti-PTTG Ab (B). In an invasive tumor (C and $\mathrm{D})$, the tumoral cells invaded the respiratory mucosae $(\mathrm{rm})$ and exhibited labeling both in cytoplasm (cp) and nuclei $(\mathrm{N})$ with anti-PTTG Ab (D). Bar $=100 \mu \mathrm{m}(\mathrm{A})$; Bar $=25 \mu \mathrm{m}(\mathrm{B}-\mathrm{D})$.
In the $\mathrm{SMtTW}_{2}$ tumors, mitoses were absent or rare with a Ki-67 nuclear index of $\leq 6 \%$. We detected no PSA-NCAM.

In the $\mathrm{SMtTW}_{3 \mathrm{pm}}$ tumors, the mitotic index and the $\mathrm{Ki}$ 67 labeling index were higher in the $\mathrm{SMtTW}_{3 \mathrm{~m}}$ tumors than in the $\mathrm{SMtTW}_{3 \mathrm{pm}}$. All $\mathrm{SMtTW}_{3}$ tumors, irrespective of the number of passages, expressed PSA-NCAM.

The positive expression of PSA-NCAM in $\mathrm{SMtTW}_{3 \mathrm{pm}}$ tumors (Daniel et al. 2000), never seen in $\mathrm{SMtTW}_{2}$ tumors, suggested that $\mathrm{SMtTW}_{3 \mathrm{pm}}$ tumors were different from $\mathrm{SMtTW}_{2}$ tumors. Proliferative marker detection, PSA-NCAM expression, and tumoral behavior suggested that $\mathrm{SMtTW}_{2}$ lineage tumors are benign, while $\mathrm{SMtTW}_{3 \mathrm{pm}}$ tumors are premalignant and $\mathrm{SMtTW}_{3 \mathrm{~m}}$ tumors malignant.

\section{Transcriptomic analysis of human PRL tumors}

We identified 33 genes able to differentiate each of the three groups of tumors (Table 3 ).

In non-invasive tumors (Table $3 \mathrm{~A}$ ), seven genes were differentially expressed when compared with the two other groups. Among them, three genes implicated in signaling pathways regulating invasion were downregulated (CRMP1 and SLITRK3) or upregulated (DCAMKL3). Three genes implicated in proliferation (CENPE, PTTG, and CCNBI) were downregulated and one gene $(K I F 13 B)$ coding for a protein associated with a tumor suppressor protein, DGL1, was upregulated.

In invasive tumors (Table 3B), 12 genes were differentially expressed when compared with the two other groups. Some genes implicated in proliferation

Table 2 Main characteristics and classification of the spontaneous mammotropic transplantable tumors in Wistar/Furth (SMtTW) rat tumors

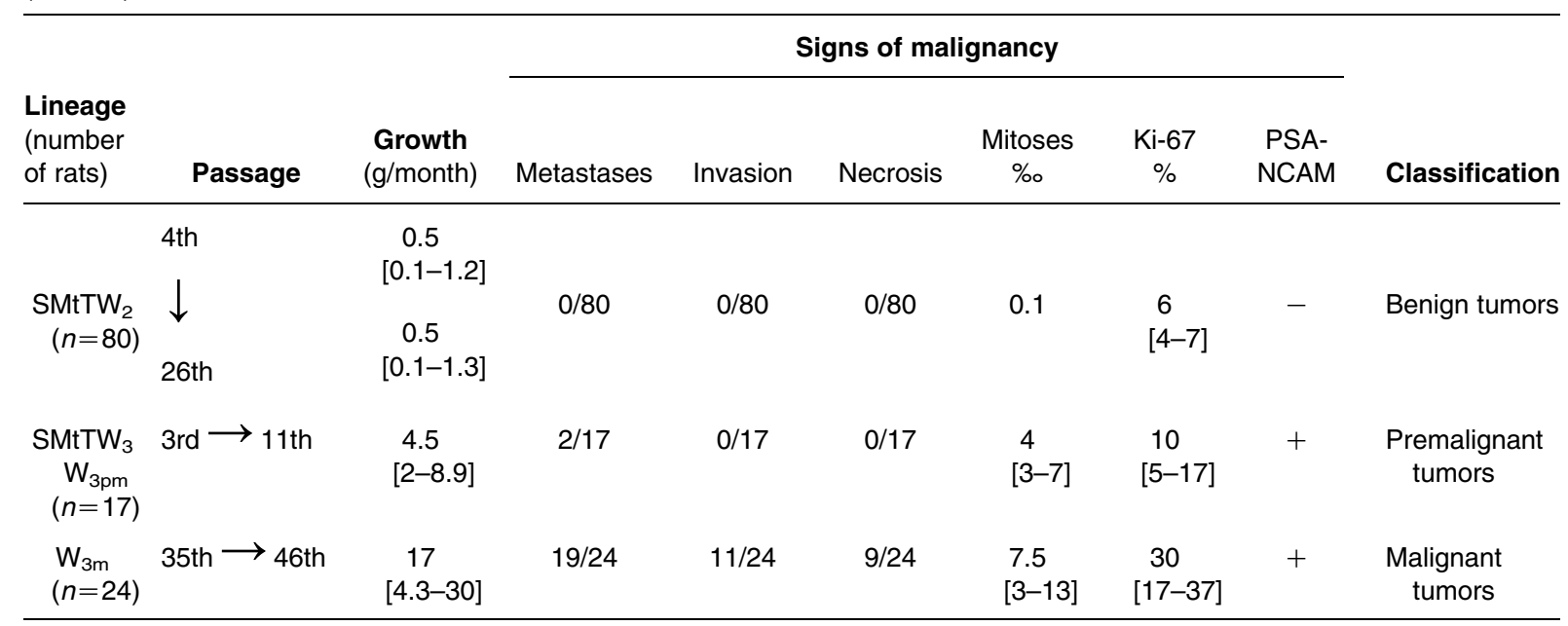

The values are the mean with the range in brackets. 


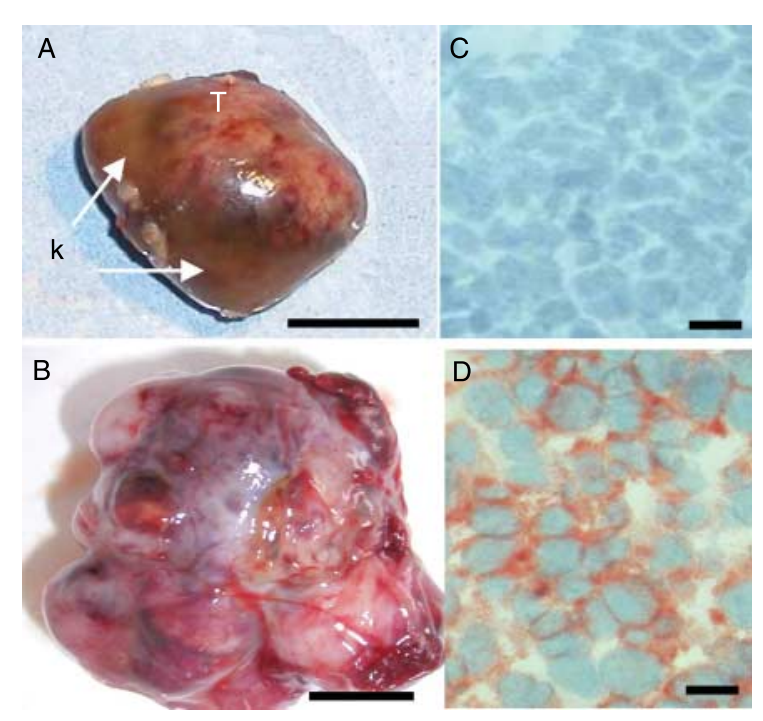

Figure 2 Gross aspect and PSA-NCAM detection in benign and malignant rat PRL tumors. Gross aspect of benign $\mathrm{SMtTW}_{2}$ tumors $(A)$ and malignant SMtTW $_{3 m}$ tumors (B): for all the passages, the $\mathrm{SMtTW}_{2}$ tumor surface is smooth and the kidney is always present. The SMtTW $3 \mathrm{~m}$ tumors are irregular and bumped, and the kidney has disappeared. T, tumor; k, kidney; bar $=1 \mathrm{~cm}$. Immunocytochemical detection of PSA-NCAM is always negative in SMtTW $\mathrm{SH}_{2}$ tumors $(\mathrm{C})$ and positive in all the $\mathrm{SMtTW}_{3}$ tumors (D); bar $=25 \mu \mathrm{m}$.

were upregulated (e.g. TRIB3 or CENPE) or downregulated (HISTIH4H and MTB). ZNF568, KIAA1729, $P H F 12$, and $P H F 19$ coding for finger proteins implicated in transcriptional regulation were upregulated.

In aggressive-invasive PRL tumors (Table 3C), among the 16 differentially regulated genes, we found: i) notable downregulation of a transcription factor implicated in pituitary development (PITX1; a member of the paired-like class of homeodomain factors $b$ ), ii) downregulation of a voltage-sensitive sodium channel $\beta$ subunit $(S C N 3 B)$, which mediates a $\mathrm{p} 53$-dependent apoptotic pathway, iii) upregulation of a disintegrin and metalloproteinase (ADAMTS6), and iv) upregulation of genes implicated in the cell cycle ( $A S K$, RACGAP1, CENPE, and AURKB).

\section{Comparison of transcriptomic analysis in rat and human PRL tumors}

To evaluate the accuracy of the histological and molecular classification of human PRL tumors, we performed microarray analyses on rat PRL tumors (data not shown). We analyzed the gene expression pattern of the molecular markers identified in the human tumor types in rat tumors. Among the 33 genes identified in the human PRL tumor analysis, 13 homologous genes were present on rat microarrays. Nine of these (Cenpe-E predicted, Pttg1, Ccnb1, KIF13b, Vom1-predicted, Pitx1, NXPh3, Racgapl-predicted, and Aurkb) showed differential expression between benign tumors $\left(\mathrm{SMtTW}_{2}\right)$, premalignant $\left(\mathrm{SMtTW}_{3 \mathrm{pm}}\right)$, and malignant $\left(\mathrm{SMtTW}_{3 \mathrm{~m}}\right)$ tumors. The results were validated by q-RTPCR on the benign $\mathrm{SMtTW}_{2}$ lineage and premalignant and malignant tumors of the $\mathrm{SMtTW}_{3}$ lineage, using normal pituitaries as the standard for gene expression. The most interesting data concerning six genes are shown in Fig. 3. As seen in human invasive and aggressive-invasive PRL tumors, we found low Aurkb and Cenpe expression levels in benign tumors and progressively increased levels in premalignant and malignant $\mathrm{SMtTW}_{3}$ tumors in the rat. Pttgl was upregulated only in rat malignant tumors with the highest levels of mRNA found in aggressive-invasive human PRL tumors. Crmp3 was upregulated exclusively in malignant rat tumors, whereas $C R M P 1$ was upregulated in invasive and aggressive-invasive human tumors. In rat tumors, we observed a progressive increase in Siat $8 b$ gene expression correlated with an increase in PSA-NCAM expression. This contrasted with human PRL tumors in which no differential expression of SIATSB was seen between the different tumor groups. Pitxl was only downregulated in malignant tumors, similar to the expression pattern seen in aggressive-invasive human tumors.

\section{Diagnostic and prognostic value of the selected genes in human PRL tumors}

To identify a set of genes that could usefully classify PRL tumors as non-invasive, invasive, and aggressive-invasive, we used the criteria of i) significant changes in expression between the three groups of tumors, ii) a known function in tumor progression, and/or iii) a common profile in human and rat. We chose 16 candidate genes, which were tested by q-RTPCR on the ten tumors used for the microarrays. The expression changes for all genes were confirmed, with a correlation ranging from 0.80 to 0.99 between microarray and q-RTPCR. To confirm the ability of the selected genes to discriminate between noninvasive, invasive, and aggressive-invasive PRL tumors, we used q-RTPCR to measure the expression of these 16 genes in the 15 other tumors. After analysis, we selected nine genes (DCAMKL3, CRMP1, ADAMTS6, PTTG1, ASK, CCNB1, AURKB, $C E N P E$, and PITX1) that showed the most significant changes between the three tumor groups. The expression levels of these genes measured by q-RTPCR on the 25 human PRL tumors are presented in Table 4. 
Table 3 Differential expression of 33 genes by microarray in ten human prolactin (PRL) tumors

\begin{tabular}{|c|c|c|c|}
\hline Name & Accession number, Unigen & FC & $P$ value \\
\hline \multicolumn{4}{|c|}{ A. Non-invasive tumors versus invasive and aggressive-invasive tumors } \\
\hline SLITRK3 ${ }^{\mathrm{a}}$ & NM_014926, Hs.101745 & -9.4 & 0.007 \\
\hline CENPE $^{\mathrm{a}, \mathrm{b}}$ & NM_001813, Hs.75573 & -5.6 & 0.012 \\
\hline PTTG1 $1^{a, b}$ & NM_004219, Hs.350966 & -3.0 & 0.002 \\
\hline $\mathrm{CCNB1}^{\mathrm{a}, \mathrm{b}}$ & NM_031966, Hs.23960 & -2.3 & 0.01 \\
\hline CRMP1 ${ }^{a, b}$ & NM_001313, Hs.135270 & -2.1 & 0.046 \\
\hline $\mathrm{KIF} 13 \mathrm{~B}^{\mathrm{a}, \mathrm{b}}$ & NM_015254, Hs.444767 & 2.2 & 0.002 \\
\hline DCAMKL3 $^{a, b}$ & AL046643, Hs.388304 & 6.6 & 0.050 \\
\hline \multicolumn{4}{|c|}{ B. Invasive tumors versus non-invasive and aggressive-invasive tumors } \\
\hline $\mathrm{HIST} 1 \mathrm{H} 4 \mathrm{H}^{\mathrm{a}}$ & N32748, Hs.421737 & -5.1 & 0.002 \\
\hline MTB, LUZP5 & T99312, Hs.18616 & -3.2 & 0.002 \\
\hline PVT1 ${ }^{a}$ & BX648921, Hs.133107 & -3.1 & 0.002 \\
\hline ZNF568 & Al281981, Hs.587993 & 2.0 & 0.004 \\
\hline GAL3ST3 & NM_033036, Hs.208343 & 2.2 & 0.002 \\
\hline TRIB3 $^{\mathrm{b}}$ & NM_021158, Hs.516826 & 2.4 & 0.003 \\
\hline CENPE $^{\mathrm{a}, \mathrm{b}}$ & NM_001813, Hs.75573 & $3.2 /-2.8$ & 0.012 \\
\hline PHF12 & NM_020889, Hs.444173 & 3.4 & 0.004 \\
\hline PSCD4 & NM_013385, Hs.170944 & 3.6 & 0.003 \\
\hline PHF19 & BX640713, Hs.460124 & 4.0 & 0.001 \\
\hline KIAA1729a & Al807149, Hs.455089 & 4.4 & 0.003 \\
\hline $\mathrm{VMO}^{\mathrm{b}}$ & NM_182566, Hs.122561 & 7.5 & 0.006 \\
\hline \multicolumn{4}{|c|}{ C. Aggressive-invasive tumors versus non-invasive and invasive tumors } \\
\hline PITX1 $^{a, b}$ & NM_002653, Hs.84136 & -11.6 & 0.003 \\
\hline TRIM36 & NM_018700, Hs.519514 & -4.3 & 0.026 \\
\hline WBSCR27 & NM_152559, Hs.162206 & -3.6 & 0.003 \\
\hline $\mathrm{SCN}_{3} \mathrm{~B}^{\mathrm{a}}$ & AB032984, Hs.4865 & -3.1 & 0.003 \\
\hline $\mathrm{NXPH} 3^{\mathrm{b}}$ & NM_007225, Hs.55069 & -2.6 & 0.003 \\
\hline TRMT1 & Al523933, Hs.515169 & -2.4 & 0.003 \\
\hline FAM111A & NM_022074, Hs.150651 & 2.0 & 0.003 \\
\hline ASK, DBF4 ${ }^{\mathrm{a}}$ & NM_006716, Hs.485380 & 2.2 & 0.002 \\
\hline RACGAP1 $1^{a, b}$ & NM_013277, Hs.505469 & 2.3 & 0.003 \\
\hline LRRCC1 & NM_033402, Hs.193115 & 2.7 & 0.003 \\
\hline PTPRE $^{\mathrm{b}}$ & NM_130435, Hs.127022 & 2.8 & 0.010 \\
\hline ADAMTS6 $^{a}$ & NM_197941, Hs.344757 & 3.6 & 0.002 \\
\hline CENPE $^{\mathrm{a}, \mathrm{b}}$ & NM_001813, Hs.75573 & 3.9 & 0.012 \\
\hline TncRNA & U60873, Hs.433995 & 4.1 & 0.018 \\
\hline FAM72A & NM_207418, Hs.339665 & 4.8 & 0.004 \\
\hline AURKB $^{\mathrm{a}, \mathrm{b}}$ & NM_004217, Hs.442658 & 5.7 & 0.003 \\
\hline
\end{tabular}

$\mathrm{FC}$ indicates the average fold change.

asixteen genes tested by q-RTPCR.

bThirteen genes found in rat whole-genome microarray slides. The nine genes of the set are in bold.

Except for one non-invasive tumor (no. 11) showing a gene expression pattern similar to that of an invasive tumor, we found a correlation between the histological markers and the expression of genes involved in invasion and proliferation (Table 5). The gene profiles were in agreement with the histological classification into three groups. Moreover, each gene was differentially expressed by q-RTPCR in the three groups of tumors with a high degree of significance ( $P=0.015$ to 0.0001 ; Table 4$)$.

On comparing these pathological and genomic markers with post-surgical outcome (Table 1), we found a very strong correlation. Indeed, all but one of the patients with non-invasive tumors were in remission 27-108 months after surgery and may today be considered as cured.
All the patients with invasive tumors presented a persistence of hyperprolactinemia and a tumoral remnant either stable under dopamine agonist or showing growth as in two patients after a long recurrence-free interval (102 and 120 months). Moreover, three out of the five aggressive-invasive tumors were resistant to dopamine agonist. A short time to recurrence $(5,12,18,21$, and 53 months) must be underlined in the five patients with aggressive-invasive tumors.

The case-control study concerning 9 patients in remission after surgery (control nos 1-3, 5-7, and 9-11) and 14 patients with persistent or recurrent PRL tumors (case nos 4, 12-15, and 17-25) revealed that eight out of the nine genes selected differentially 

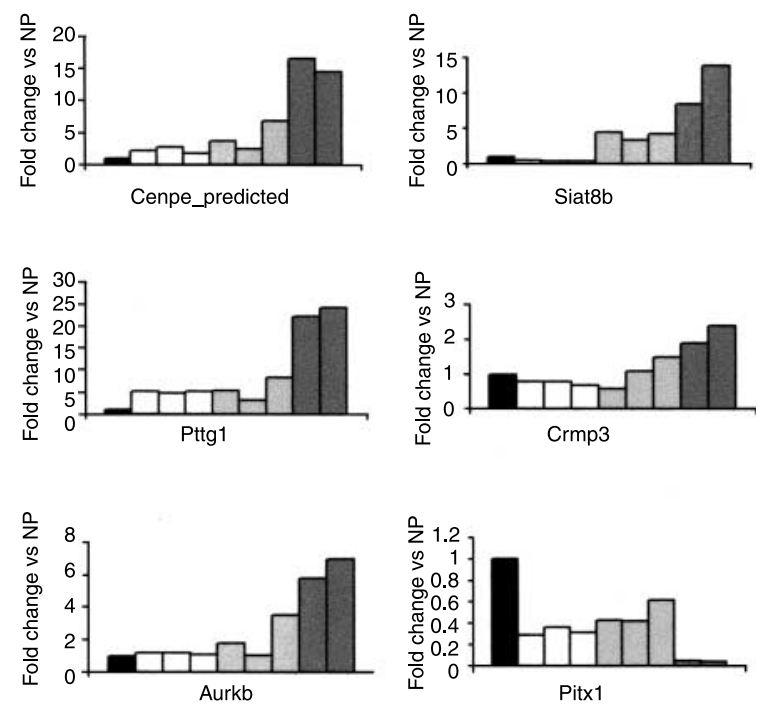

Figure 3 Gene expression analysis in rat PRL tumors using qRTPCR. Gene expression by q-RTPCR in rat PRL tumors. $\square$ Benign tumors (SMtTW 2 passages 10,19 , and 21); premalignant tumors (SMtTW Spm $_{3}$ passages 3,4 , and 6 ); malignant tumors (SMtTW ${ }_{3 m}$ passages 41 and 42 ). Within a group, the earlier passage is shown on the left. Normal pituitary. Expression of the genes in normal pituitary tissue was used as the standard and set to 1 .

expressed between patients in remission and those with persistent or recurrent tumors, with a high degree of significance ( $P=0.05$ to 0.002$)$. Only the expression of PTTG showed no correlation with clinical course $(P=0.258)$.

\section{Discussion}

The 2004 WHO classification of tumors of endocrine organs emphasized the advances that have occurred in the molecular biology and pathogenesis of pituitary tumors (Lloyd et al. 2004). However, some authors (Al-Shraim \& Asa 2006, Figarella-Branger \& Trouillas 2006) have pointed out the lack of reliable histological markers for the diagnosis of malignancy and of 'atypical adenoma' (adenoma with aggressive behavior). Using a combination of histological markers and genomic analysis, here we have identified a set of up- or downregulated genes implicated in invasion and proliferation differentially expressed with a high degree of significance in the three groups of human PRL tumors, non-invasive, invasive, and aggressiveinvasive tumors. The correlations with the surgical outcome evidenced different clinical courses. The potential importance of these genes has been reinforced by the presence of a similar altered set in a rat model with benign and malignant PRL tumors.
As previously described, no histological markers, per se, made it possible to differentiate between noninvasive and invasive tumors. However, the association of histological features, including mitoses, the Ki-67 index, and nuclear staining for p53 and PTTG, suggested a subtype in the invasive group (named aggressive-invasive), which correlated with different clinical behaviors. The non-invasive PRL micro- or macroadenomas without proliferation and invasion markers are totally removed by surgery and the patients remain cured after a long-time follow-up. The invasive PRL macroadenomas sometimes with signs of proliferation (few mitoses and low Ki-67 index) and PSANCAM expression are not totally surgically removed: the PRL plasma levels remain increased and a long time to recurrence may be observed. The aggressiveinvasive PRL tumors are characterized by a high proliferation rate (numerous mitoses, high Ki-67 index, nuclear labeling of PTTG and P53), a frequent dopamine resistance, and a short time to recurrence.

Our genomic study confirms the differential expression of previously described genes in pituitary tumors when compared with normal pituitary (data not shown), such as Insulin-like growth factor-binding protein 5 (IGFBP5), NOV, WnT, and Notch, found by microarray (Evans et al. 2001, Moreno et al. 2005, Morris et al. 2005), or of some growth factors or their receptors, such as transforming growth factor $\beta$ (TGF $\beta$ ), IGFr, FGFb, and FGFbr found by other techniques (reviewed by Ray \& Melmed 1997, Asa \& Ezzat 1998). Galectin-3, previously reported to be a marker of invasion and malignancy (Riss et al. 2003), was either not expressed or was restricted to endothelial cells in all but one case in our PRL tumors. Previous microarray studies of different functional types and subtypes of pituitary tumors (Evans et al. 2001, Moreno et al. 2005, Morris et al. 2005) gave disappointing results for diagnosis. In these studies, the comparison of tumors and normal pituitary identified genes implicated in tumorigenesis rather than in tumoral progression (Farrell 2006). The focus on PRL tumors as an individual tumor entity and radiological and histological classification provides a new approach for the identification of tumoral progression markers.

Indeed, our genomic analysis allowed the identification of a set of differentially expressed genes that differentiates these three groups of PRL tumors. In the invasive tumors, two invasion genes (ADAMTS6 and $C R M P 1)$ were upregulated and one (DCAMKL3) downregulated. The metalloprotease MMP9 detected by immunocytochemistry in invasive PRL tumors by Wass' group (Turner et al. 2000) was not differentially 


\begin{tabular}{|c|c|c|c|c|c|c|c|c|c|}
\hline Tumors & DCAMKL3 & CRMP1 & ADAMTS6 & PTTG1 & ASK & CCNB1 & AURKB & CENPE & PITX1 \\
\hline \multicolumn{10}{|c|}{ Non-invasive } \\
\hline 1 & 4.61 & 0.66 & 3.93 & 2.25 & 0.51 & 0.95 & 4.98 & 0.50 & 0.20 \\
\hline 2 & 0.79 & 0.41 & 0.06 & 1.75 & 0.28 & 0.36 & 0.39 & 0.30 & 0.17 \\
\hline 3 & 1.74 & 1.02 & 2.03 & 2.13 & 1.38 & 3.18 & 5.99 & 0.80 & 0.34 \\
\hline 4 & 5.34 & 0.90 & 3.28 & 0.88 & 1.03 & 1.68 & 2.04 & 0.50 & 0.43 \\
\hline 5 & 2.26 & 0.71 & 0.69 & 2.00 & 0.82 & 1.23 & 4.15 & 0.50 & 0.64 \\
\hline 6 & 1.50 & 0.54 & 2.30 & 21.25 & 0.10 & 0.14 & 1.66 & 0.01 & 0.57 \\
\hline $7^{a}$ & 1.87 & 0.59 & 0.03 & 0.75 & 0.64 & 0.86 & 2.50 & 0.30 & 0.20 \\
\hline $8^{a}$ & 3.39 & 0.41 & 0.00 & 1.13 & 0.46 & 0.64 & 2.56 & 0.20 & 0.14 \\
\hline $9^{a}$ & 5.00 & 0.80 & 0.98 & 3.00 & 0.79 & 0.59 & 3.01 & 0.30 & 0.15 \\
\hline 10 & 1.11 & 2.44 & 0.79 & 1.00 & 0.79 & 1.91 & 1.86 & 2.20 & 0.69 \\
\hline 11 & 3.92 & 3.27 & 11.48 & 12.50 & 0.92 & 2.86 & 11.09 & 2.80 & 0.10 \\
\hline Means & $2.76 \pm 0.54$ & $0.85 \pm 0.19$ & $1.41 \pm 0.45$ & $3.61 \pm 1.97$ & $0.68 \pm 0.12$ & $1.15 \pm 0.29$ & $2.91 \pm 0.53$ & $0.56 \pm 0.19$ & $0.35 \pm 0.07$ \\
\hline \multicolumn{10}{|l|}{ Invasive } \\
\hline 12 & 0.74 & 3.71 & 11.48 & 4.88 & 1.54 & 2.77 & 5.66 & 1.30 & 1.22 \\
\hline 13 & 8.84 & 2.41 & 6.89 & 0.88 & 0.38 & 0.59 & 2.78 & 3.20 & 2.68 \\
\hline 14 & 0.42 & 3.78 & 4.59 & 2.25 & 1.36 & 2.55 & 4.89 & 2.80 & 1.44 \\
\hline 15 & 0.95 & 2.44 & 8.20 & 2.00 & 1.18 & 2.73 & 2.92 & 1.80 & 1.01 \\
\hline 16 & 0.74 & 1.63 & 13.11 & 3.38 & 0.90 & 2.50 & 9.96 & 5.40 & 1.52 \\
\hline $17^{\mathrm{a}}$ & 0.24 & 2.95 & 6.89 & 1.00 & 1.56 & 3.55 & 2.67 & 2.10 & 1.30 \\
\hline $18^{a}$ & 0.58 & 1.15 & 6.23 & 4.00 & 1.33 & 2.86 & 5.37 & 8.50 & 0.67 \\
\hline $19^{a}$ & 0.58 & 1.66 & 0.05 & 4.13 & 0.69 & 1.45 & 4.60 & 1.90 & 0.31 \\
\hline $20^{a}$ & 0.32 & 2.41 & 5.57 & 3.25 & 0.87 & 2.45 & 6.30 & 3.60 & 0.91 \\
\hline Means & $1.49 \pm 0.92$ & $2.46 \pm 0.30$ & $7.00 \pm 1.27$ & $2.86 \pm 0.47$ & $1.09 \pm 0.13$ & $2.38 \pm 0.29$ & $4.96 \pm 0.77$ & $3.4 \pm 0.76$ & $1.23 \pm 0.22$ \\
\hline \multicolumn{10}{|c|}{ Aggressive-invasive } \\
\hline 21 & 1.87 & 3.22 & 25.25 & 4.63 & 2.38 & 4.18 & 17.44 & 5.30 & 2.38 \\
\hline 22 & 2.63 & 2.44 & 32.79 & 12.50 & 3.45 & 4.55 & 16.57 & 10.00 & 3.45 \\
\hline $23^{a}$ & 0.47 & 2.37 & 20.00 & 17.63 & 3.67 & 4.45 & 22.53 & 32.10 & $0.00^{\mathrm{b}}$ \\
\hline $24^{a}$ & 1.76 & 1.51 & 27.54 & 26.00 & 2.79 & 4.55 & 34.20 & 9.80 & $0.03^{\mathrm{b}}$ \\
\hline $25^{\mathrm{a}}$ & 0.87 & 1.73 & 20.00 & 41.63 & 3.95 & 7.91 & 46.82 & 10.70 & $0.01^{b}$ \\
\hline Means & $1.52 \pm 0.38$ & $2.25 \pm 0.30$ & $25.11 \pm 2.42$ & $20.48 \pm 6.33$ & $3.25 \pm 0.29$ & $5.13 \pm 0.70$ & $27.51 \pm 5.76$ & $13.58 \pm 4.72$ & $1.17 \pm 0.73(0.01 \pm 0.009)^{b}$ \\
\hline$P$ value & 0.0086 & 0.0046 & 0.0001 & 0.0045 & 0.0004 & 0.0002 & 0.0004 & 0.0001 & 0.0147 \\
\hline
\end{tabular}

Expression of genes in normal pituitary tissue was used as a standard and set to 1 .

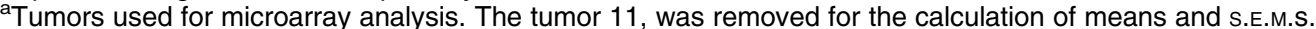

${ }^{\text {b}}$ Three more aggressive-invasive tumors with very low PITX1 mRNA expression only taken into account for the means in bracket. 


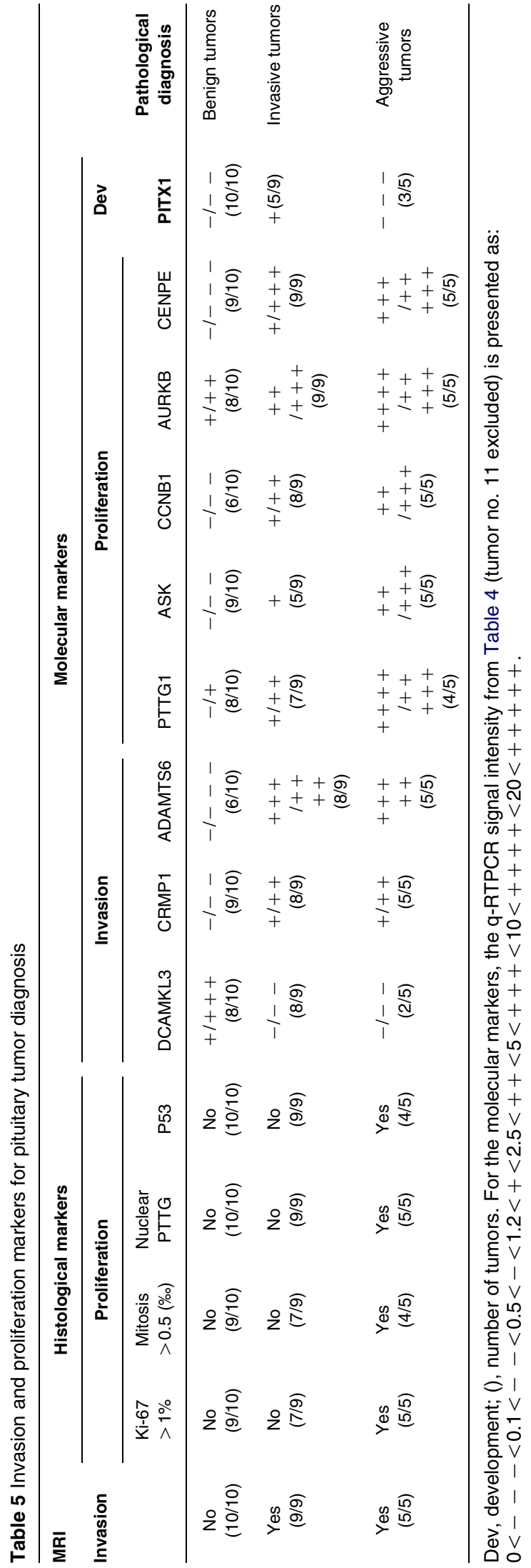

expressed at mRNA levels in our series. In the aggressive-invasive tumors, in addition to ADAMTS6 and $C R M P 1$ upregulation, five proliferation genes (PTTG, ASK, CCNB1, AURKB, and CENPE) were highly upregulated and one differentiation gene (PITX1) downregulated.

The upregulation of Pttg, Aurkb, Cenpe, and Crmp and the non-expression of Pitxl in rat malignant PRL tumors suggest the involvement of these genes in malignancy. Functionally, ASK, PTTG, AURKB, $C C N B 1$, and $C E N P E$ are involved in the cell cycle, ADAMTS6 in the control of extracellular matrix components, PSA-NCAM and CRMP in migration, and PITX1 in pituitary differentiation.

Among the genes involved in mitosis, the dramatically increased $P T T G$ expression in human aggressiveinvasive tumors and rat malignant PRL tumors confirmed the pioneering studies by Melmed's group (Pei \& Melmed 1997, Zhang et al. 1999), which showed a correlation between PTTG expression and tumor invasion. Interestingly, while $P T T G$ expression was restricted to the cytoplasm in non-invasive and invasive tumors, it was seen in both the cytoplasm and nucleus in aggressive-invasive tumors. Overexpression of PTTG and its translocation from the cytoplasm to the nucleus may induce inappropriate sister chromatid exchange, resulting in genetic instability and aneuploidy (Yu et al. 2003). AURKB, with an expression pattern similar to that of PTTG, inhibits microtubule depolymerization (Andrews et al. 2003). Deregulation of $A U R K B, C E N P E$, and $A S K$ is associated with multiple defects of the mitotic machinery (Yao et al. 2000, Vigneron et al. 2004). Interestingly, promoters of these genes, including ADAMTS6, are under the control of the same transcription factors, E2F1 and E2F4, implicated in cell proliferation (Balasubramanian et al. 1999, Crosby \& Almasan 2004). E2F1 activation stimulates pituitary tumorigenesis (Fedele et al. 2006) and E2F4 loss suppresses the development of both pituitary and thyroid tumors in Rb mutant mice (Lee et al. 2002).

Some of these upregulated genes have been described in general carcinogenesis. PTTG, considered as a tumor-inducing gene (Heaney et al. 1999), is a component of the 17-gene expression signature markers of metastatic potential (Ramaswamy et al. 2003). A link between $A U R K B$ expression and carcinogenesis has been found in different types of cancers (Katayama et al. 1999, Smith et al. 2005). Finally, as recently suggested (Whitfield et al. 2006), the proliferation genes can be used as biomarkers for cancer diagnosis and prognosis. 
In terms of tumor invasion, ADAMTS6 seems to be an interesting marker. The adamalysin-thrombospondin proteinases (ADAMs) are a family of 20 members containing metalloproteinase, thrombospondin, and disintegrin motifs (Tang 2001). ADAMs are involved in tissue organization during embryogenesis and angiogenesis. Some ADAMs with matrix-degrading activity might be involved in cell invasion. The function of ADAMTS6 is unknown, but induction of this gene has been seen in breast carcinoma (Porter et al. 2005). $C R M P 1$ and $C R M P 3$ belong to a family of five members. CRMP1, which showed increased expression in almost all invasive and aggressive-invasive PRL tumors in the present study, has been implicated in lung carcinoma, invasion, and metastasis (Chang et al. 2004) and the pathogenesis of a paraneoplastic neurological disease (Honnorat et al. 1999).

Only a few genes involved in pituitary differentiation have been found to show modulated expression in invasive PRL tumors: SIAT8B, coding for an enzyme involved in sialylation (Kojima et al. 1996), and PITX, a pan-pituitary regulator of transcription (Tremblay et al. 1998) more recently described as a suppressor of tumorigenicity (Kolfschoten et al. 2005). The high expression of Siat8 in the rat confirmed the presence of the PSA-NCAM in rat malignant PRL tumors (Daniel et al. 2000). However, SIAT8B or PITX1 showed no consistent up- or downregulation in invasive human PRL tumors. Despite this discrepancy, SIAT8B upregulation or PITXI downregulation unambiguously indicated an aggressive-invasive PRL tumor. Moreover, the dopamine resistance in the three tumors with downregulation of PITXI is consistent with the tumoral dedifferentiation found in some human PRL carcinomas (Delgrange et al. 1997, Kaltsas et al. 2005) and in rat malignant tumors (Trouillas et al. 1999).

The identification of nine genes differentially expressed in the three groups of PRL tumors improves the pathological diagnosis. The upregulation of genes implicated in invasion can confirm the invasiveness of the tumor in the usual absence of the histological proof, or it can give the diagnosis in case of a doubtful MRI or an absence of invasive signs, as in our patient no. 11 . Until now, the pituitary pathologist was not able to give a prognosis to the clinician. Our study demonstrates that a high significant correlation between the clinical course and a differential expression of a set of relevant genes makes it possible to predict aggressiveness of PRL tumors.

The events involved in the pathogenesis of invasive and aggressive-invasive tumors are a matter of debate. Proposed mechanisms include the transformation of preexisting non-invasive or invasive adenoma or the de novo malignant transformation of pituitary cells. The rat PRL tumors have premalignant, malignant $\left(\mathrm{SMtTW}_{3}\right)$, and benign $\left(\mathrm{SMtTW}_{2}\right)$ phenotypes. This rat model shows an evolution to malignancy with events underlying a multistep transformation.

In conclusion, combined histological and molecular analyses may improve the pathological diagnosis of PRL tumors. This procedure is the more reliable for predicting the recurrence potential of these tumors. This set of nine genes involved in proliferation, invasion, and differentiation might provide useful new markers for treatment guidance. The rat model will allow progress in identifying the multiple steps involved in carcinogenesis and testing new therapeutic strategies for PRL tumors.

\section{Acknowledgements}

We are greatly indebted to the Neurobiotec Bank, $\mathrm{P}$ Roy, E Dantony, and E Decullier for help in statistical analysis and $\mathrm{T}$ Barkas for help with the English translation. Programme Hospitalier de Recherche Clinique National 2006-2008 (no 27-43); Institut National de la Santé et de la Recherche Médicale; Région Rhône-Alpes (France); and Ligue Contre le Cancer Rhône-Alpes 2006. The authors declare that there is no conflict of interest that would prejudice the impartiality of this scientific work.

\section{References}

Al-Shraim M \& Asa SL 2006 The 2004 World Health Organization classification of pituitary tumors: what is new? Acta Neuropathologica 111 1-7.

Andrews PD, Knatko E, Moore WJ \& Swedlow JR 2003 Mitotic mechanics: the auroras come into view. Current Opinion in Cell Biology 15 672-683.

Asa SL \& Ezzat S 1998 The cytogenesis and pathogenesis of pituitary adenomas. Endocrine Reviews 19 798-827.

Balasubramanian S, Ahmad N \& Mukhtar H 1999 Upregulation of E2F transcription factors in chemically induced mouse skin tumors. International Journal of Oncology 15 387-390.

Chang CC, Shih JY, Jeng YM, Su JL, Lin BZ, Chen ST, Chau YP, Yang PC \& Kuo ML 2004 Connective tissue growth factor and its role in lung adenocarcinoma invasion and metastasis. Journal National Cancer Institute 96 364-375.

Crosby ME \& Almasan A 2004 Opposing roles of E2Fs in cell proliferation and death. Cancer Biology \& Therapy 3 1208-1211.

Daniel L, Trouillas J, Renaud W, Chevallier P, Gouvernet J, Rougon G \& Figarella-Branger D 2000 Polysialylatedneural cell adhesion molecule expression in rat pituitary 
transplantable tumors (spontaneous mammotropic transplantable tumor in Wistar-Furth rats) is related to growth rate and malignancy. Cancer Research 60 80-85.

Delgrange E, Trouillas J, Maiter D, Donckier J \& Tourniaire J 1997 Sex-related difference in the growth of prolactinomas: a clinical and proliferation marker study. Journal of Clinical Endocrinology and Metabolism 82 2102-2107.

Delgrange E, Sassolas G, Perrin G, Jan M \& Trouillas J 2005 Clinical and histological correlations in prolactinomas, with special reference to bromocriptine resistance. Acta Neurochirurgica 147 751-758.

Evans CO, Young AN, Brown MR, Brat DJ, Parks JS, Neish AS \& Oyesiku NM 2001 Novel patterns of gene expression in pituitary adenomas identified by complementary deoxyribonucleic acid microarrays and quantitative reverse transcription-polymerase chain reaction. Journal of Clinical Endocrinology and Metabolism 86 3097-3107.

Ezzat S, Zheng L, Zhu XF, Wu GE \& Asa SL 2002 Targeted expression of a human pituitary tumor-derived isoform of FGF receptor-4 recapitulates pituitary tumorigenesis. Journal of Clinical Investigation 109 69-78.

Farrell WE 2006 Pituitary tumours: findings from whole genome analyses. Endocrine-Related Cancer $\mathbf{1 3}$ 707-716.

Fedele M, Visone R, De Martino I, Troncone G, Palmieri D, Battista S, Ciarmiello A, Pallante P, Arra C, Melillo RM et al. 2006 HMGA2 induces pituitary tumorigenesis by enhancing E2F1 activity. Cancer Cell 9 459-471.

Fevre-Montange M, Champier J, Szathmari A, Wierinckx A, Mottolese C, Guyotat J, Figarella-Branger D, Jouvet A \& Lachuer J 2006 Microarray analysis reveals differential gene expression patterns in tumors of the pineal region. Journal of Neuropathology and Experimental Neurology 65 675-684.

Figarella-Branger D \& Trouillas J 2006 The new WHO classification of human pituitary tumors: comments. Acta Neuropathologica 111 71-72.

Grossman AB 2006 The 2004 World Health Organization classification of pituitary tumors: is it clinically helpful? Acta Neuropathologica 111 76-77.

Gurlek A, Karavitaki N, Ansorge O \& Wass JA 2007 What are the markers of aggressiveness in prolactinomas? Changes in cell biology, extracellular matrix components, angiogenesis and genetics European Journal of Endocrinology 156 143-153.

Heaney AP, Horwitz GA, Wang Z, Singson R \& Melmed S 1999 Early involvement of estrogen-induced pituitary tumor transforming gene and fibroblast growth factor expression in prolactinoma pathogenesis. Nature Medicine 5 1317-1321.

Honnorat J, Byk T, Kusters I, Aguera M, Ricard D, Rogemond V, Quach T, Aunis D, Sobel A, Mattei MG et al. 1999 Ulip/CRMP proteins are recognized by autoantibodies in paraneoplastic neurological syndromes. European Journal of Neuroscience 11 4226-4232.
Hsu DW, Hakim F, Biller BM, de la Monte S, Zervas NT, Klibanski A \& Hedley-Whyte ET 1993 Significance of proliferating cell nuclear antigen index in predicting pituitary adenoma recurrence. Journal of Neurosurgery 78 753-761.

Jaffrain-Rea ML, Di Stefano D, Minniti G, Esposito V, Bultrini A, Ferretti E, Santoro A, Faticanti Scucchi L, Gulino A \& Cantore G 2002 A critical reappraisal of MIB-1 labelling index significance in a large series of pituitary tumours: secreting versus non-secreting adenomas. Endocrine-Related Cancer 9 103-113.

Kaltsas GA, Nomikos P, Kontogeorgos G, Buchfelder M \& Grossman AB 2005 Clinical review: Diagnosis and management of pituitary carcinomas. Journal of Clinical Endocrinology and Metabolism 90 3089-3099.

Katayama H, Ota T, Jisaki F, Ueda Y, Tanaka T, Odashima S, Suzuki F, Terada Y \& Tatsuka M 1999 Mitotic kinase expression and colorectal cancer progression.

Journal National Cancer Institute 91 1160-1162.

Knosp E, Kitz K \& Perneczky A 1989 Proliferation activity in pituitary adenomas: measurement by monoclonal antibody Ki-67. Neurosurgery 25 927-930.

Kojima N, Tachida Y, Yoshida Y \& Tsuji S 1996 Characterization of mouse ST8Sia II (STX) as a neural cell adhesion molecule-specific polysialic acid synthase. Requirement of core alpha1,6-linked fucose and a polypeptide chain for polysialylation. Journal of Biological Chemistry 271 19457-19463.

Kolfschoten IG, van Leeuwen B, Berns K, Mullenders J, Beijersbergen RL, Bernards R, Voorhoeve PM \& Agami R 2005 A genetic screen identifies PITX1 as a suppressor of RAS activity and tumorigenicity. Cell $\mathbf{1 2 1}$ 849-858.

Lee EY, Cam H, Ziebold U, Rayman JB, Lees JA \& Dynlacht BD 2002 E2F4 loss suppresses tumorigenesis in Rb mutant mice. Cancer Cell 2 463-472.

Levy A, Hall L, Yeudall WA \& Lightman SL 1994 p53 gene mutations in pituitary adenomas: rare events. Clinical Endocrinology 41 809-814.

Lloyd RV, Scheithauer BW, Kuroki T, Vidal S, Kovacs K \& Stefaneanu L 1999 Vascular endothelial growth factor (VEGF) expression in human pituitary adenomas and carcinomas. Endocrine Pathology 10 229-235.

Lloyd RV, Kovacs K, Young WF Jr, Farrel WE, Asa SL, Trouillas J, Kontogeorgeos G, Sano T, Scheithauer BW \& Horvath E 2004 Pituitary tumors: introduction. In World Health Organization Classification of Tumours. Pathology and Genetics of Tumours of Endocrine Organs, Eds RA DeLellis, RV Lloyd, PU Heitz \& C Eng. Lyon: IARC Press.

Meij BP, Lopes MB, Ellegala DB, Alden TD \& Laws ER Jr 2002 The long-term significance of microscopic dural invasion in 354 patients with pituitary adenomas treated with transsphenoidal surgery. Journal of Neurosurgery 96 195-208.

Moreno CS, Evans CO, Zhan X, Okor M, Desiderio DM \& Oyesiku NM 2005 Novel molecular signaling and 
classification of human clinically nonfunctional pituitary adenomas identified by gene expression profiling and proteomic analyses. Cancer Research 65 10214-10222. Morris DG, Musat M, Czirjak S, Hanzely Z, Lillington DM, Korbonits M \& Grossman AB 2005 Differential gene expression in pituitary adenomas by oligonucleotide array analysis. European Journal of Endocrinology 153 143-151.

Pei L \& Melmed S 1997 Isolation and characterization of a pituitary tumor-transforming gene (PTTG). Molecular Endocrinology 11 433-441.

Pei L, Melmed S, Scheithauer B, Kovacs K \& Prager D 1994 H-ras mutations in human pituitary carcinoma metastases. Journal of Clinical Endocrinology and Metabolism 78 842-846.

Porter S, Clark IM, Kevorkian L \& Edwards DR 2005 The ADAMTS metalloproteinases. Biochemical Journal 386 15-27.

Ramaswamy S, Ross KN, Lander ES \& Golub TR 2003 A molecular signature of metastasis in primary solid tumors. Nature Genetics 33 49-54.

Ray D \& Melmed S 1997 Pituitary cytokine and growth factor expression and action. Endocrine Reviews 18 206-228.

Riss D, Jin L, Qian X, Bayliss J, Scheithauer BW, Young WF Jr, Vidal S, Kovacs K, Raz A \& Lloyd RV 2003 Differential expression of galectin-3 in pituitary tumors. Cancer Research 63 2251-2255.

Smith SL, Bowers NL, Betticher DC, Gautschi O, Ratschiller D, Hoban PR, Booton R, Santibanez-Koref MF \& Heighway J 2005 Overexpression of aurora B kinase (AURKB) in primary non-small cell lung carcinoma is frequent, generally driven from one allele, and correlates with the level of genetic instability. British Journal of Cancer 93 719-729.

Tang BL 2001 ADAMTS: a novel family of extracellular matrix proteases. International Journal of Biochemistry and Cell Biology 33 33-44.

Tremblay JJ, Lanctot C \& Drouin J 1998 The pan-pituitary activator of transcription, Ptx1 (pituitary homeobox 1), acts in synergy with SF-1 and Pit1 and is an upstream regulator of the Lim-homeodomain gene Lim3/Lhx3. Molecular Endocrinology 12 428-441.
Trouillas J, Girod C, Claustrat B, Joly-Pharaboz MO \& Chevallier P 1990 Spontaneous prolactin transplantable tumor in the Wistar/Furth rat (SMtTW): a new animal model of human prolactinoma. Cancer Research $\mathbf{5 0}$ 4081-4086.

Trouillas J, Chevallier P, Remy C, Rajas F, Cohen R, Calle A, Hooghe-Peters EL \& Rousset B 1999 Differential actions of the dopamine agonist bromocriptine on growth of SMtTW tumors exhibiting a prolactin and/or a somatotroph cell phenotype: relation to dopamine D2 receptor expression. Endocrinology 140 13-21.

Trouillas J, Daniel L, Guigard MP, Tong S, Gouvernet J, Jouanneau E, Jan M, Perrin G, Fischer G, Tabarin A et al. 2003 Polysialylated neural cell adhesion molecules expressed in human pituitary tumors and related to extrasellar invasion. Journal of Neurosurgery 98 1084-1093.

Turner HE, Nagy Z, Esiri MM, Harris AL \& Wass JA 2000 Role of matrix metalloproteinase 9 in pituitary tumor behavior. Journal of Clinical Endocrinology and Metabolism 85 2931-2935.

Vigneron S, Prieto S, Bernis C, Labbe JC, Castro A \& Lorca T 2004 Kinetochore localization of spindle checkpoint proteins: who controls whom? Molecular and Cellular Biology 15 4584-4596.

Whitfield ML, George LK, Grant GD \& Perou CM 2006 Common markers of proliferation. Nature Reviews. Cancer 6 99-106.

Yao X, Abrieu A, Zheng Y, Sullivan KF \& Cleveland DW 2000 CENP-E forms a link between attachment of spindle microtubules to kinetochores and the mitotic checkpoint. Nature Cell Biology 2 484-491.

Yu R, Lu W, Chen J, McCabe CJ \& Melmed S 2003 Overexpressed pituitary tumor-transforming gene causes aneuploidy in live human cells. Endocrinology 144 4991-4998.

Zhang X, Horwitz GA, Heaney AP, Nakashima M, Prezant TR, Bronstein MD \& Melmed S 1999 Pituitary tumor transforming gene (PTTG) expression in pituitary adenomas. Journal of Clinical Endocrinology and Metabolism 84 761-767. 